\title{
COMPARISON OF VARIOUS CLINICAL MEASUREMENTS OF BLOOD PRESSURE WITH THE SELF-DETERMINATION TECHNIQUE IN NORMOTENSIVE COLLEGE MALES
}

\author{
S. Julius, M.D.*, N. F. McGinn, Ph.D., E. Harburg, Ph.D. and \\ S. W. HOOBLER, M.D. \\ The Department of Internal Medicine and The Program of Social Psychology, University of \\ Michigan, Ann Arbor, Michigan
}

(Received 22 July 1963)

\begin{abstract}
A PERSON's blood pressure under the usual conditions of daily life may be quite different from that in the physician's office. This is particularly the case and quite important for young individuals referred to a physician for the first time because of a chance finding of a slight blood pressure elevation. In theory, variability among blood pressure measures in a given subject might be reduced by a more careful control of the experimental situation and by repetitive measurements. If a person could measure his own blood pressure, at least the emotional influence of the patient-physician relationship would be in part excluded. A special type of cuff, described by BLAQuiER and HOOBLER [1], has been designed for this purpose. These authors have compared self-determined office blood pressure readings of normotensive and hypertensive subjects to those performed by professional personnel. This type of observation is extended, in this report, to the blood pressures as self-determined away from the physician's office. Such home readings are compared to a series taken on the same normal subject by the physician. In this way it was hoped to obtain information concerning the relationship between the home blood pressure of the subject and the readings taken in the office environment.
\end{abstract}

\section{E T H O D S}

Blood pressure was determined by five trained examiners on 800 University of Michigan white male students undergoing a routine physical examination required of all new registrants. The 50 subjects with 'high' and 50 with 'low' systolic blood pressures (over $140 \mathrm{~mm}$ and under $110 \mathrm{~mm}$ ) were selected for further study. There were no significant differences in the diastolic blood pressure between the two groups, nor were any over $90^{\circ} \mathrm{mm}$ diastolic. The average age of the students was 21.3 years ranging from 17 to 25 . On a later occasion, by appointment, 90 of the subjects returned for an hour-long blood pressure study conducted by the senior author in every case using the same sphygmomanometer.

*Present address: Department of Internal Medicine, University Medical School, Rebro, Zagreb, Yugoslavia. 
At the end of the hour's examination the method for self-determination of blood pressure was explained. The diastolic reading was to be taken at the disappearance of sound. The subject then took two separate readings with the self-determination blood pressure cuff*. Only individuals whose own determination was very close to the examiner's were permitted to take their own blood pressure readings away from the office. This represented 90 per cent of those exposed to the procedure. These 81 subjects, who subsequently received a remuneration for their services, were instructed to take readings in the sitting position before breakfast, before dinner, and before retiring at night for two consecutive days.

By these methods several blood pressure variables were obtained, which are defined as follows:

1. Office casual blood pressure. A single reading taken in the sitting position immediately after the subject, previously selected for a 'high' (greater than $140 \mathrm{~mm}$ ) or 'low' (less than $110 \mathrm{~mm}$ ) systolic reading, came to the physician's office for a re-evaluation of his blood pressure status.

2. Resting blood pressure. Taken recumbent after $20 \mathrm{~min}$ of bed rest in a quiet office environment, the average of three successive determinations.

3. Median home blood pressure. The median of the six readings which the subjects took at home $\dagger$.

4. Maximal home difference. The difference, in $\mathrm{mm} \mathrm{Hg}$, between the highest and lowest home blood pressure readings.

5. Casual to resting difference. The difference between the casual and the resting blood pressure, disregarding the sign of the difference.

The data obtained were transferred to punch cards and analyzed by a correlation statistic (Pearson's $r$ ) on electronic computers.

\section{R E S U L T S}

Although the subjects to be studied were selected on the basis of initially high or low systolic blood pressure readings, there was a normal distribution of blood pressure on the second or 'office casual blood pressure' as a result of a marked regression toward the mean in the case of the second reading, taken under more relaxed circumstances when the student returned by appointment. This measurement more closely resembles the one usually taken by the physician in the office when a subject is referred for an elevated blood pressure. Since it may be objected that two subgroups are nevertheless represented in the final analysis, the correlations within each subgroup were computed; since they did not differ substantially from the results obtained when correlations were computed for the group as a whole, the results obtained by the latter method only are presented below.

Table 1 presents the means and standard deviations of the various measures, and their intercorrelations. The mean of the casual systolic blood pressure was $128.9 \mathrm{~mm}$, with a standard deviation of \pm 14.6 . This compares with a mean of $133.3 \pm 11.3$

*Manufactured by the Propper Manufacturing Company. For details see BlaQuier and HOOBLER [1].

†The median was used as a more accurate measure of central tendency than the mean in that it is less sensitive to the extreme values which the six readings showed for many individuals. These medians were normally distributed. 
Table 1. Means, STANDard deviations and intercorrelations* of VARIOUS bloOd PRESSURE MEASURES AND PHYSICAL CHARACTERISTICS $(n=81)$

\begin{tabular}{|c|c|c|c|c|c|c|c|}
\hline \multirow{2}{*}{ Mean } & \multirow{2}{*}{ S.D. } & \multirow[b]{2}{*}{ SYSTOLIC } & \multirow{2}{*}{$\begin{array}{l}\text { Office } \\
\text { casual }\end{array}$} & \multirow[b]{2}{*}{ Resting } & \multicolumn{3}{|c|}{ Home readings } \\
\hline & & & & & Lowest & Median & Highest \\
\hline $\begin{array}{r}128.9 \\
122.5 \\
116.3 \\
126.0 \\
133.3 \\
29.4 \\
165.1 \\
16.3\end{array}$ & $\begin{array}{r}14.6 \\
13.6 \\
11.1 \\
11.2 \\
11.3 \\
2.8 \\
26.6 \\
17.9\end{array}$ & $\begin{array}{l}\text { Casual (office) } \\
\text { Resting } \\
\text { Lowest home } \\
\text { Median home } \\
\text { Highest home } \\
\text { Arm girth (cm) } \\
\text { Weight (lb) } \\
\text { Overweight } \dagger\end{array}$ & $\begin{array}{l}0.81 \\
0.56 \\
0.52 \\
0.47 \\
0.44 \\
0.60 \\
0.48\end{array}$ & $\begin{array}{l}0.58 \\
0.63 \\
0.61 \\
0.41 \\
0.54 \\
0.46\end{array}$ & $\begin{array}{l}0.90 \\
0.75 \\
0.46 \\
0.60 \\
0.59\end{array}$ & $\begin{array}{l}0.88 \\
0.48 \\
0.66 \\
0.62\end{array}$ & $\begin{array}{l}0.46 \\
0.57 \\
0.58\end{array}$ \\
\hline & & DIASTOLIC & & & & & \\
\hline $\begin{array}{l}64.9 \\
60.9 \\
62.8 \\
71 \cdot 4 \\
78.6\end{array}$ & $\begin{array}{r}14.6 \\
9.6 \\
10 \cdot 6 \\
10 \cdot 2 \\
10.8\end{array}$ & $\begin{array}{l}\text { Casual (office) } \\
\text { Resting } \\
\text { Lowest home } \\
\text { Median home } \\
\text { Highest home }\end{array}$ & $\begin{array}{l}0.31 \\
0.24 \\
0.21 \\
0.16\end{array}$ & $\begin{array}{l}0.46 \\
0.42 \\
0.37\end{array}$ & $\begin{array}{l}0.83 \\
0.89\end{array}$ & 0.71 & \\
\hline
\end{tabular}

${ }^{*} r=0.23$ is necessary for significance at the 0.05 level of significance, and a correlation of 0.29 is necessary for the 0.01 level.

† According to Metropolitan Life Insurance standards.

for the highest home blood pressure measurement. The mean of the resting systolic blood pressure was $122.5 \pm 13.6 \mathrm{~mm} \mathrm{Hg}$, while the average of the lowest home blood pressure readings was $116.3 \pm 11.1$. Neither of these differences was statistically significant applying a $t$-test for correlated means. The degree of intercorrelation for all systolic measures was highly significant.

Comparison of means for the diastolic blood pressure measurements showed somewhat larger differences. The average casual diastolic reading was $64.9 \pm 14.6$ $\mathrm{mm} \mathrm{Hg}$. This compared with a mean of $78.6 \pm 10.8$ for the highest home diastolic blood pressure. This difference was statistically significant and suggests an overestimation of the reading by the subject at home. The mean of the resting diastolic measure was $60.9 \pm 9.6 \mathrm{~mm} \mathrm{Hg}$, while that of the lowest home diastolic was $62.8 \pm 10.6$. In this case also the home reading was higher but the difference did not achieve statistical significance. Intercorrelations among different diastolic measurements were less uniform than for the systolic readings. The casual diastolic blood pressure did not correlate significantly with the different home readings. However, the resting diastolic pressure showed some degree of correlation with the various home measurements. The home diastolic measurements correlated highly among themselves.

Figures 1 and 2 have been constructed for the purpose of comparing the resting blood pressure with some other measurements taken on the same individual. Figure 1 compares the casual readings to the resting values in the office. There is a general agreement between these readings in the same individual, especially for the systolic measurement. However, a decline in the systolic reading during the 

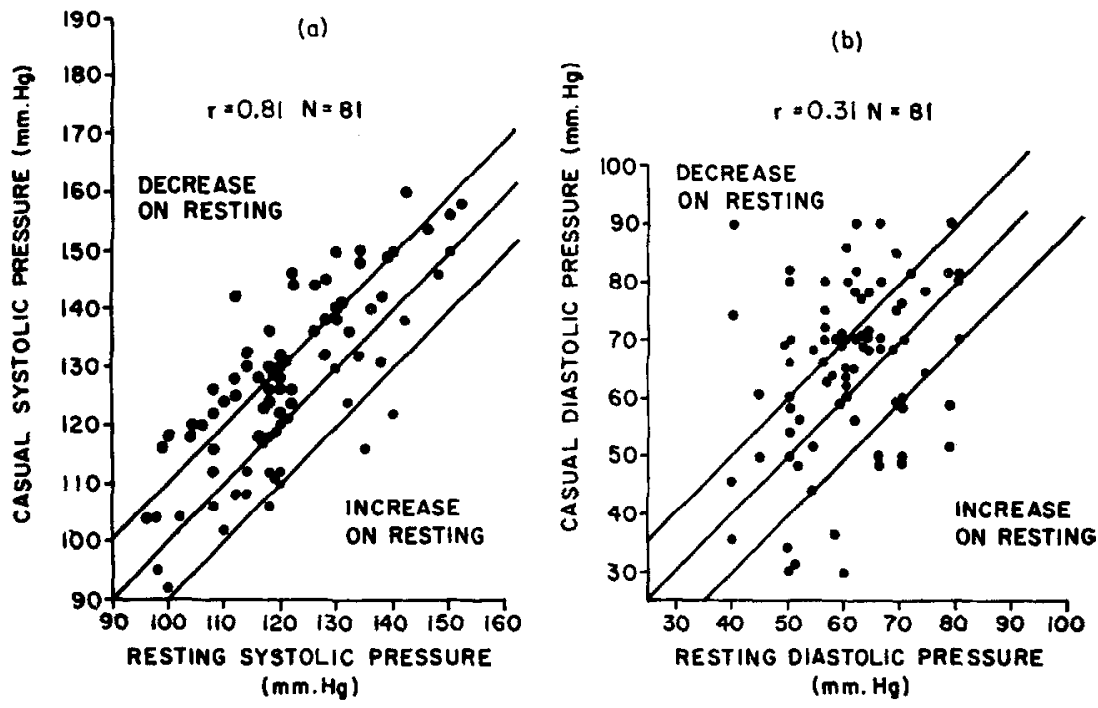

Fig. 1 (a), (b). Relationship between casual blood pressures taken at start of examination and resting blood pressures taken 20 min later. See Table 1 for level of significance of $r$. Upper and lower lines represent deviations of more or less than $10 \mathrm{~mm} \mathrm{Hg}$ from perfect concordance between the two readings.

(a)

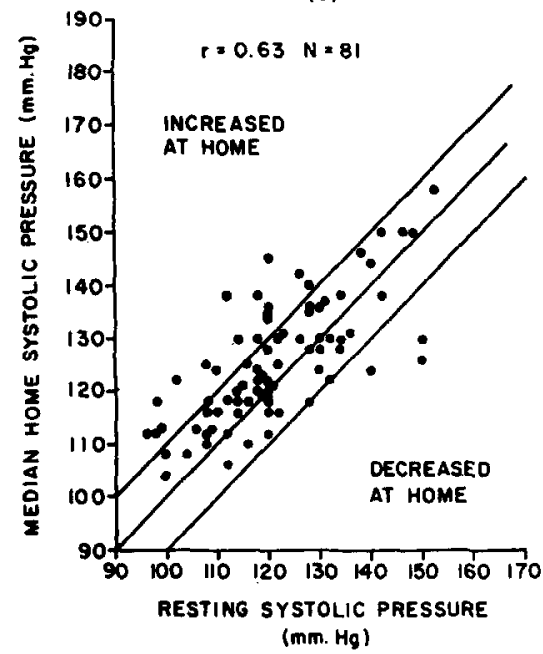

(b)

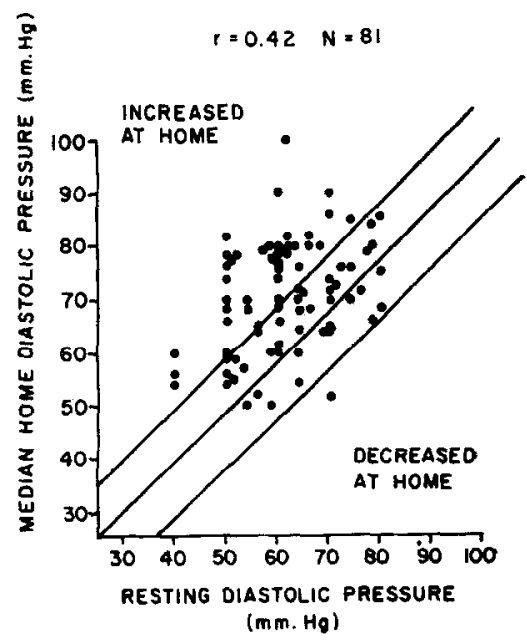

Fig. 2 (a), (b). Relationship between resting blood pressures taken by physician and median of six home readings taken by subjects.

rest period is usually observed. The diastolic level shows a similar trend but to a lesser extent.

Figure 2 compares the median home measurement, as taken by the subject, to the resting blood pressure taken by the physician in the office. The median home reading is higher on the average than the resting level in the office. The difference is of about the same magnitude as between casual and the resting values (Table 1 
and Fig. 1a). Correlations between home and office diastolic blood pressures are lower and this is probably due to inability to accurately detect the diastolic end-point.

If the subjects were systematically ignoring minor differences in the blood pressure reading, the home measurements from one time to another should tend to be highly similar. This did not appear to be the case since the maximal home difference for systolic readings was $17.1 \pm 8.0 \mathrm{~mm} \mathrm{Hg}$ and for the diastolic $16.1 \pm 8.3$ $\mathrm{mm} \mathrm{Hg}$. These differences substantially exceed the casual to resting differences obtained by the physician in the office. They suggest a considerable degree of variability of the blood pressure at different times of the day.

If home blood pressure measurements exhibit the same association with increased weight as has been repeatedly observed for office measurements, the reliability of the home readings would be further supported. Reference to Table 1 shows that indeed there are similar correlations between home blood pressure measurements and arm girth, actual weight, or overweight as when these latter variables are correlated with office blood pressure readings.

\section{I S C U S S I O N}

The readings obtained by multiple self-determinations of blood pressure in the home have been compared with various office readings. Our studies indicate that such methods for the determination of systolic blood pressure would appear to be reliable despite the relatively short instruction period required. Of our college subjects, 90 per cent were able to report meaningful readings as judged by correlations with office blood pressure, spontaneous variability of readings, and the recognized association between higher blood pressures and body weight. The selfdetermination of diastolic blood pressure yielded weaker correlations possibly as a result of difficulty in recognizing the end-point of disappearance of sound. These observations suggest that the inexperienced subject tends to record too high a reading for this measurement.

A considerable variability of blood pressure throughout the day was recorded by the subject-as great or greater than that observed on repetitive readings in the physician's office. This confirms the observations of GLocK and associates [2].

Since the report of AYMAN and GoLDSHINE [3] a number of authors have reported studies concerning the relationship of office and home blood pressures. In these instances the home reading has been performed by a member of the patient's household rather than by the subject himself. Recently several clinics have used self-determination techniques in hypertensive subjects but only with reference to control of drug dosage [4-6]. In this report we have used the method to relate office to home blood pressure levels and to determine the spontaneous variability of the blood pressure, in normotensive subjects, preparatory to the use of the technique in the hypertensive patient.

A somewhat unexpected result of our study was the finding of a wide disparity between two casual systolic blood pressures taken on the same person several weeks apart. Thus a student placed in the initially high blood pressure category (over $140 \mathrm{~mm} \mathrm{Hg}$ ) exhibited a normal reading later on while another with an initially low first reading (below $110 \mathrm{~mm} \mathrm{Hg}$ ) frequently rose to the normal range (110-140 
$\mathrm{mm} \mathrm{Hg}$ ). On re-examination, 100 subjects selected for either high or low casual readings completely lost their identity. Disparities of as much as $30 \mathrm{~mm} \mathrm{Hg}$ in the systolic blood pressure occurred on re-examination. We must conclude that the casual systolic blood pressure of apparently normal individuals is subject to such great fluctuation that little clinical importance can be attached to single readings even when they are extremely high or low. Such an experience was shared by THACKER [7] in a study of young college students: only 25 per cent of those with initially high readings continued to have high levels throughout four successive determinations.

\section{O N CLUS I O N}

The systolic blood pressure as determined by the subject in the home after a brief period of instruction is reasonably accurate. When diurnal variations by this technique are compared to the casual-resting differences as recorded in the physician's office, at least as great a variation is observed. Where subjects were classified on the basis of extremes of a single casual blood pressure, they were found to lose their identity on re-examination. Variations between casual systolic office blood pressure readings as well as between home readings in the apparently normotensive subject are much wider than is usually appreciated.

Acknowledgements-This work was supported by Grant No. H2578, U.S. Department of Health, Education and Welfare. We are indebted to Dr. MoRLEY BeCKeTT, Director of Student Health Service, University of Michigan, for his generous cooperation in this study.

\section{R E F E R E N C ES}

1. Blaquier, P. and Hoobler, S. W.: A new blood pressure cuff for self-determination of the blood pressure, Univ. Mich. med. Bull. 23, 356, 1957

2. Glock, C. Y., Vought, R. L., Clark, E. G. and Schwertzer, M. D.: Studies in hypertension: III. Variability of daily blood pressure measurements in the same individuals over a three week period, J. chron. Dis. 4, 469, 1956.

3. Ayman, D. and Goldshine, A. D.: Blood pressure determinations by patients with essential hypertension. I. The difference between clinic and home readings before treatment, Amer. J. med. Sci. 200, 465, 1940.

4. Schroeder, H. A. : Management of arterial hypertension, Amer. J. Med. 17, 540, 1954.

5. Dustan, H. P., Corcoran, A. C., Schneckloth, R. and Page, I. H.: Combination therapy of severe hypertension with ganglion blockers and reserpine, Circulation 12, 698, 1955.

6. FreIs, E. D.: In Pathogenesis of Essential Hypertension: Proc. Prague Symp. p. 111. Edited by CORT, J. H., Fencl, V., HeJl, Z. and JIRKA, J. State Medical Publishing House, Prague, Czechoslovakia, 1960.

7. THACKer, E. A.: A comparative study of normal and abnormal blood pressures among university students, including the cold pressor test, Amer. Heart J. 20, 89, 1940 